\title{
Micronutrients intake, morbidity pattern and life style of muslim (Sunni) people of 25 to 35 years
}

\author{
Vinita Singh and Pooja Singh
}

\begin{abstract}
One of the five fundamental rituals of Islam, the religion professed by over one billion people, is fasting during the month of Ramadan, muslims (Sunni) neither eat nor drink anything from dawn till sunset (Bener et al., 2001). Maximum 25.96 per cent increased calcium was found in 25 to 35 years of age group and 11.61 per cent of increase calcium was found in 35 to 45 years of age group. Maximum 20.33 per cent increased vitamin A was found in 35 to 45 years of age group and 12.28 per cent deficient vitamin A was found in 25 to 35 years of age group. Maximum 25.85 per cent deficient folic acid was found in 25 to 35 years of age group and 25.75 per cent deficient folic acid was found in 35 to 45 years of age group. Riboflavin and folic acid intake was found lower as compared to recommended dietary allowances and thiamine content was found high because they were consumed biryani in their diet. 22.0 per cent of muslim people were having joint pain frequently while 15.0 per cent of were having occasional joint pain problem, 18.0 per cent were having frequently high B.P while 10.0 per cent occasional high B.P problem, 5.0 per cent of muslim people were having any other history of disease, 100.0 per cent respondents were doing worship in the morning and believe in religion, 58.0 per cent respondents were going to morning walk 46.0 per cent respondents were doing any field work in the morning, 26.0 per cent respondents were going to place work by vehicle ( car / two wheeler).
\end{abstract}

Key Words : Vitamin, Minerals, Morbidity pattern, Life style

How to cite this article : Singh, Vinita and Singh, Pooja (2019). Micronutrients intake, morbidity pattern and life style of muslim (Sunni) people of 25 to 35 years. Food Sci. Res. J., 10(2): 217-220, DOI : 10.15740/HAS/FSRJ/10.2/217-220.Copyright@ 2019: Hind Agri-Horticultural Society. 